\title{
Response of Solidago canadensis clones to competition
}

\author{
Deborah E. Goldberg \\ Department of Biology, University of Michigan, Ann Arbor, MI 48109-1048
}

\begin{abstract}
Summary. Transplants of ten Solidago canadensis clones were grown under high and low competition in the field to determine whether clones differed in survival, growth, and reproduction under natural conditions. Transplants had higher probability of survival and flowering and were larger in all measures of size when competition was experimentally reduced. Clones differed in almost all these measures of success, but only when variance among transplants within clones was reduced by excluding transplants that experienced heavy herbivore damage. Differences among clones were more apparent under low competition than under high competition, despite higher coefficients of variation within clones under low competition. Adjusting transplant size for initial size (parent ramet rhizome mass) did not change these results, although clones did differ in parent rhizome mass. All of these results suggest that there is little potential for selection to discriminate among these clones. Despite the strong differences in transplant performance between the competition treatments and among clones, the clones did not differ in competitive ability-almost none of the clone $\times$ competition interactions were significant. In addition, the measures of success of each clone were usually positively correlated between the high and low competition treatments, suggesting there were no tradeoffs between performance under high and low competition for these clones.
\end{abstract}

Key words: Solidago canadensis var. scabra-Genotype $\times$ environment interactions - Plant competition - Clonal variation - Herbivory

Within most plant populations, there is enormous phenotypic variation in components of fitness among individuals. Although we have abundant evidence of genetic variation among individuals within populations (Hamrick 1979; Ellstrand and Roose 1987), there is still relatively little field data on the effects of genotypic variation and especially, interactions between genotype and environment in determining phenotypic variation within natural plant populations (Solbrig and Simpson 1977; Turkington and Harper 1979; Fowler and Antonovics 1981; Antonovics 1984; Kelly and Clay 1987; see Zangerl and Bazzaz 1983, 1984; Garbutt and Bazzaz 1987 for greenhouse experiments). An understanding of how relative fitness of genotypes changes in different environments is critical for two reasons. First, the existence of genotype-environment interactions is a necessary condition for the evolution of genetic adaptation to small-scale environmental heterogeneity. Second, genotype-environment interactions provide an opportunity to examine the mechanisms underlying the tradeoffs between traits that confer success in different environments.

One particularly important aspect of the environment to an individual plant is its competitive environment. Several studies have demonstrated differences in competitive ability among populations under field or greenhouse conditions (Solbrig and Simpson 1977; Ford 1981; Martin and Harding 1981; Heywood and Levin 1984; Aarssen and Turkington 1985 b; Schoen et al. 1986). However, studies of genetically-based variation in competitive ability within populations are rare (greenhouse: Turkington 1979; Aarssen and Turkington 1985a; Ennos 1985; field: Turkington and Harper 1979; Kelley and Clay 1987).

In this paper, I report results of a field experiment using clonal replicates of a perennial herb, Solidago canadensis var. scabra growing in different competitive environments. I ask whether clones differ in survival, reproduction and size under field conditions and whether clones respond differently to low and high levels of diffuse competition, i.e. whether clone and clone $\times$ competitive environment interactions, respectively, contribute significantly to total phenotypic variance. The experimental design also allowed assessment of the effect of initial size (rhizome storage from parental ramets) and size early in a growing season on subsequent transplant performance.

\section{Methods}

\section{Species and site description}

Solidago canadensis var. scabra (Muhl.) T. and G. $(=S$. altissima L.; see Werner et al. 1980 for a discussion of the taxonomy of $S$. canadensis) is a clonal perennial herb that is often dominant in fields abandoned from agriculture throughout the northeast and northcentral USA. The clones used in this experiment were taken from Louden Field at the W.K. Kellogg Biological Station (KBS) in southwestern Michigan, USA. The field was abandoned from agriculture in 1951 and (in the area of the parent clones) is currently dominated by $S$. canadensis and several perennial grasses, including Bromus inermis, Agropyron repens, Phleum pratense, and Poa pratensis.

The site of the experiment was a nearby field (Bailey Field) that had no goldenrod but was also dominated by perennial grasses, especially Agropyron repens and Poa pratensis. A $10 \times 10 \mathrm{~m}$ portion of the field was rototilled in 
September 1983, just before the experiments were initiated. Ten transects, each $10 \mathrm{~m}$ long and $1 \mathrm{~m}$ apart were established. Twenty plots, each $50 \mathrm{~cm}$ in diameter, were established along each transect. The vegetation in the plots the next May was a mixture of perennial grasses that had regrown from rhizome fragments, primarily Poa pratensis and Agropyron repens.

\section{Target collection and planting}

Twenty ramets from each of 10 distinct clones in Louden Field were collected and transplanted into Bailey Field between 30 September and 7 October 1983. Transplant units were rhizomes of currently flowering stems, including the new rhizome buds that give rise to the next season's stems. Height of the flowering stems was measured and then the stems were cut to $5 \mathrm{~cm}$ above the soil surface. A tulip bulber was used to take a $8 \mathrm{~cm}$ diameter core of soil, rhizome, and roots $10-12 \mathrm{~cm}$ deep around the base of each stem (Werner 1988). Hartnett and Bazzaz (1983) have shown that ramet survival and growth did not differ when ramets were severed from adults between August and October, suggesting that storage of material was complete by the time the transplants were collected. The soil was washed off the roots and rhizomes and a number of measurements taken to use in estimating parent rhizome mass (see below). The transplant were then assigned to plots in Bailey Field at random. On the same day as collection, one transplant was replanted into the center of each $50 \mathrm{~cm}$ diameter experimental plot.

\section{Estimation of initial rhizome mass}

To estimate parent rhizome mass of each transplant, I washed all soil from each parent ramet, measured stem diameter and height, weighed the entire transplant, and then subtracted an estimate of stem mass, using a regression of stem mass on stem volume from a separate sample of transplants. The separate sample consisted of 10 ramets $(5$ from each for 2 clones; these clones were not used in the experiment) collected and measured in the same way as the experimental transplants. Stem volume was calculated as (average stem radius) ${ }^{2} \times \mathrm{pi} \times$ height and was highly correlated with stem wet mass (stem mass $=0.024+0.881$ (stem volume), $\left.\mathrm{r}^{2}=0.97, \mathrm{df}=8, P<0.001\right)$.

\section{Competition treatments}

On 12 May 1984, the vegetation in 107 of the 200 plots (chosen at random) was treated with a $5 \%$ solution of a contact herbicide, glyphosate (Roundup). Roundup has been found to have no residual soil effect and kills only actively metabolizing plants (Baird et al. 1971). Target transplants were about $5 \mathrm{~cm}$ tall at this time and were covered with a plastic bag to prevent contact with the herbicide. The solution was applied to the leaves of all other plants in the plot with a sponge. In all plots which had had herbicide applied, $70-80 \%$ of the aboveground parts of the perennial vegetation died within 10 days after the application of herbicide.

\section{Early transplant census}

The transplants were censused for emergence, size, and herbivore damage on 22 May 1984. All but four of all transplants that eventually emerged aboveground did so by this census. The height of each transplant and the length of the longest fully expanded leaf was measured. In addition, I recorded whether or not any herbivore damage had occurred by assigning plants to 1 of 5 damage classes: none, light leaf damage (no leaves with more than $50 \%$ of the leaf eaten), heavy leaf damage (some leaves with more than $50 \%$ of the leaf eaten), terminal meristem eaten but none or light leaf damage, and terminal meristem eaten and heavy leaf damage (defined as above). Based on preliminary analyses, these 5 classes were collapsed into 2 classes for the analyses reported below: none-light damage (no leaf damage or no leaves with $>50 \%$ of the leaf eaten) and heavy damage (some leaves with $>50 \%$ of the leaf eaten and/or terminal meristem eaten). No attempt was made to determine what animals caused the damage, although rabbits are a likely source of the terminal meristem damage.

\section{Harvest}

The transplant and all potential competitors growing in each $50 \mathrm{~cm}$ diameter plot were harvested on 6-13 October 1984. All plants growing in the plots except for the experimental transplants were clipped with scissors at ground lev$\mathrm{el}$, dried at $65 \mathrm{C}$ for 48 hours, and weighed. Both aboveground and belowground parts of the experimental transplants were harvested and dried at $65 \mathrm{C}$ for 48 hours. The height of each transplant was measured to the top of the terminal meristem, including the inflorescence if present. The transplants were then divided into stems, leaves, inflorescences, roots, new rhizomes, and current rhizome and each part weighed to the nearest $\mathrm{mg}$. The parent rhizome was usually mostly decomposed and its mass was not included in the analyses below.

\section{Analysis}

Because later life history stages could be affected by early stages (e.g. emergence and size in May by parent rhizome mass, survival and October size by parent rhizome mass or size in May), regressions and ANCOVA's were used to analyse the effects of these continuous variables and how they differ in their effect among clones and the competition treatments. Comparisons among clones, competition treatments, and hervivore damage classes for continuous variables were conducted with 1 and 2 way ANOVA's and ANCOVA's. G tests were used to test for effects of the main factors on categorical variables (e.g. emergence, survival, flowering). All statistical analyses were performed with the BMDP statistical package (Dixon 1983).

Although the measures of size in October were all highly positively correlated with each other, I report separate analyses for each biomass component because patterns of clonal differentiation differed among the size measures. All of the October size measures, but not the May size measures, had significantly heterogeneous variances between the competition treatments, but not usually among clones. Log transformation of these characters usually homogenized the variances so all ANOVA and ANCOVA results reported below for October size characters used log-transformed data. The exceptions to both these generalizations were the measures of sexual and vegetative reproduction (inflorescence mass and new rhizome mass). For these variables, variances were heterogeneous among clones and between competition treatments even after log transformation because many transplants were too small to reproduce by either mode. 
Nonparametric comparisons among clones and between competition treatments gave equivalent results to the ANOVA's for these characters so the parametric results are reported here.

\section{Results}

\section{Transplant demography}

Overall transplant success was high. Of the 198 transplants planted (two transplants in one clone were lost), 189 $(95.5 \%)$ emerged aboveground in May and $85.2 \%$ $(161 / 189)$ of these transplants survived to the harvest in October. Only $27 \%(43 / 161)$ of the surviving transplants flowered. Only transplants that emerged were included in the analyses for May census variables and only surviving transplants were included in the analyses for October census variables.

\section{Effects of initial size}

Transplants that emerged in May had larger parent ramet rhizome mass than transplants that did not emerge (Table 1). Survival from May to October was not affected by parent rhizome mass, but transplants that flowered had larger parent ramet rhizome mass than did transplants that remained vegetative (Table 1). Almost all measures of aboveground transplant size in both May and October were significantly positively correlated with parent ramet rhizome mass and parent height (Table 2). Of the belowground biomass components, only current rhizome mass was significantly correlated with both parent size measures (Table 2). The correlations with parent ramet rhizome mass were usually stronger than the correlations with parent ramed height (Table 2). Similarly, transplants that were larger in May were more likely to survive and flower (Table 1) and were larger in most measures of size in October (Table 2).

\section{Effects of competition and herbivore damage}

The herbicide treatment resulted in a large decrease in total aboveground mass of potential competitors in each plot. Mean biomass of neighbors of the transplants in the low competition (herbicided) plots was $28.35 \mathrm{~g}(\mathrm{~s}=7.64, N=$ 107) compared to $63.38 \mathrm{~g} \mathrm{(} \mathrm{s}=12.30, N=91)$ in the high competition (control) plots. The vegetation in the low competition plots also had a higher proportion of annual plants by weight $(32 \%)$ than did the high competition plots $(4 \%)$. The annuals almost all germinated after application of the herbicide.

Percent emergence was unaffected by the competition treatments initiated 10 days before the census $(\mathrm{G}=0.62$, $\mathrm{df}=1, P>0.10)$. Surprisingly, transplants were significantly larger in May in the high competition treatment, but only those with heavy herbivore damage (Fig. 1, Table 3). This resulted in significant competition $\times$ herbivore damage interactions for both measures of May size (Table 3). Overall, transplants with heavy herbivore damage were significantly smaller in May than transplants with none-light damage (Table 3, Fig. 1).

Transplants in the high competition treatment were twice as likely to be heavily damaged by herbivores $(18.2 \%)$ than transplants in the low competition treatment $(8.9 \%)$, although the difference was only marginally significant $(\mathrm{G}=3.54, \mathrm{df}=1, P=0.06)$.
Table 1. Effect of parental rhizome mass and transplant height in May on transplant emergence, survival and flowering. T-tests were used to compare mean parent rhizome mass and May height between transplants with different fates. Analyses were performed on untransformed data

\begin{tabular}{|c|c|c|c|c|c|c|c|c|}
\hline & \multicolumn{4}{|c|}{ Parent rhizome mass $(\mathrm{g})$} & \multicolumn{4}{|c|}{ May height $(\mathrm{cm})$} \\
\hline & mean & s.d. & $n$ & $t$ & mean & s.d. & $N$ & $t$ \\
\hline Emerged & 3.251 & 1.570 & 189 & $4.65^{*}$ & - & - & - & - \\
\hline Unemerged & 2.311 & 1.006 & 8 & & - & - & - & - \\
\hline Survived & 3.510 & 1.586 & 161 & $0.05^{\mathrm{ns}}$ & 10.6 & 4.8 & 157 & $7.95^{*}$ \\
\hline Died & 3.584 & 1.503 & 28 & & 7.9 & 3.9 & 28 & \\
\hline Flowered & 4.144 & 1.932 & 43 & $9.91 * * *$ & 11.9 & 4.8 & 42 & $4.19^{*}$ \\
\hline Vegetative & 3.279 & 1.377 & 118 & & 10.1 & 4.7 & 115 & \\
\hline
\end{tabular}

ns $P>0.05 ; * P \leq 0.05 ; * * * P \leq 0.001$

Table 2. Correlations between size of parent ramets, size of transplants in May and size of transplants in October. All transplants were included. All October size measures were log transformed prior to analysis

Correlation coefficients

\begin{tabular}{|c|c|c|c|}
\hline \multicolumn{2}{|c|}{ Parent ramet } & \multicolumn{2}{|c|}{ May transplant } \\
\hline height $^{\mathrm{a}}$ & $\begin{array}{l}\text { rhizome } \\
\text { mass }^{b}\end{array}$ & height $^{\mathrm{c}}$ & $\begin{array}{l}\text { length of } \\
\text { longest } \\
\text { leaf }\end{array}$ \\
\hline
\end{tabular}

May transplant size

Length longest leaf

$0.17 * \quad 0.47^{* * * *}$

October transplant size

\begin{tabular}{lllll} 
Height & $0.23^{* *}$ & $0.37^{* * *}$ & $0.47^{* * *}$ & $0.28^{* *}$ \\
Stem mass & $0.26^{* *}$ & $0.37^{* * *}$ & $0.44^{* * *}$ & $0.28^{* *}$ \\
Leaf mass & $0.23^{* *}$ & $0.19^{*}$ & 0.14 & 0.14 \\
Root mass & 0.15 & 0.15 & 0.09 & 0.12 \\
Current rhizome mass & $0.19^{*}$ & $0.30^{* *}$ & $0.32^{* * *}$ & $0.25^{* *}$ \\
New rhizome mass & 0.11 & 0.12 & $0.21^{* *}$ & $0.21^{* *}$ \\
Inflorescence mass & 0.01 & $0.21^{* *}$ & $0.20^{* *}$ & 0.12 \\
Total mass & $0.23^{* *}$ & $0.30^{* *}$ & $0.28^{* *}$ & $0.22^{* *}$ \\
\hline
\end{tabular}

* $P \leq 0.05$, ** $P \leq 0.01, * * * P \leq 0.001$

a $N=140$ (October aboveground characters), $N=136$ (May characters and October belowground and total mass)

b $N=159$ (October aboveground characters), $N=155$ (May characters and October belowground and total mass)

c $N=155$ (May characters and aboveground characters), $N=151$ (October belowground and total mass)

Probability of survival and flowering and almost all measures of size in October were significantly higher in the low competition treatment, and most measures were also higher in the none-light herbivore damage class (Table 3, Fig. 1). For all of the October size measures except height, high competition resulted in more of a decrease in size than did heavy herbivore damage (Fig. 1). None of the interactions between the effects of competition and herbivore damage were significant for characters measured in October (Table 3). 

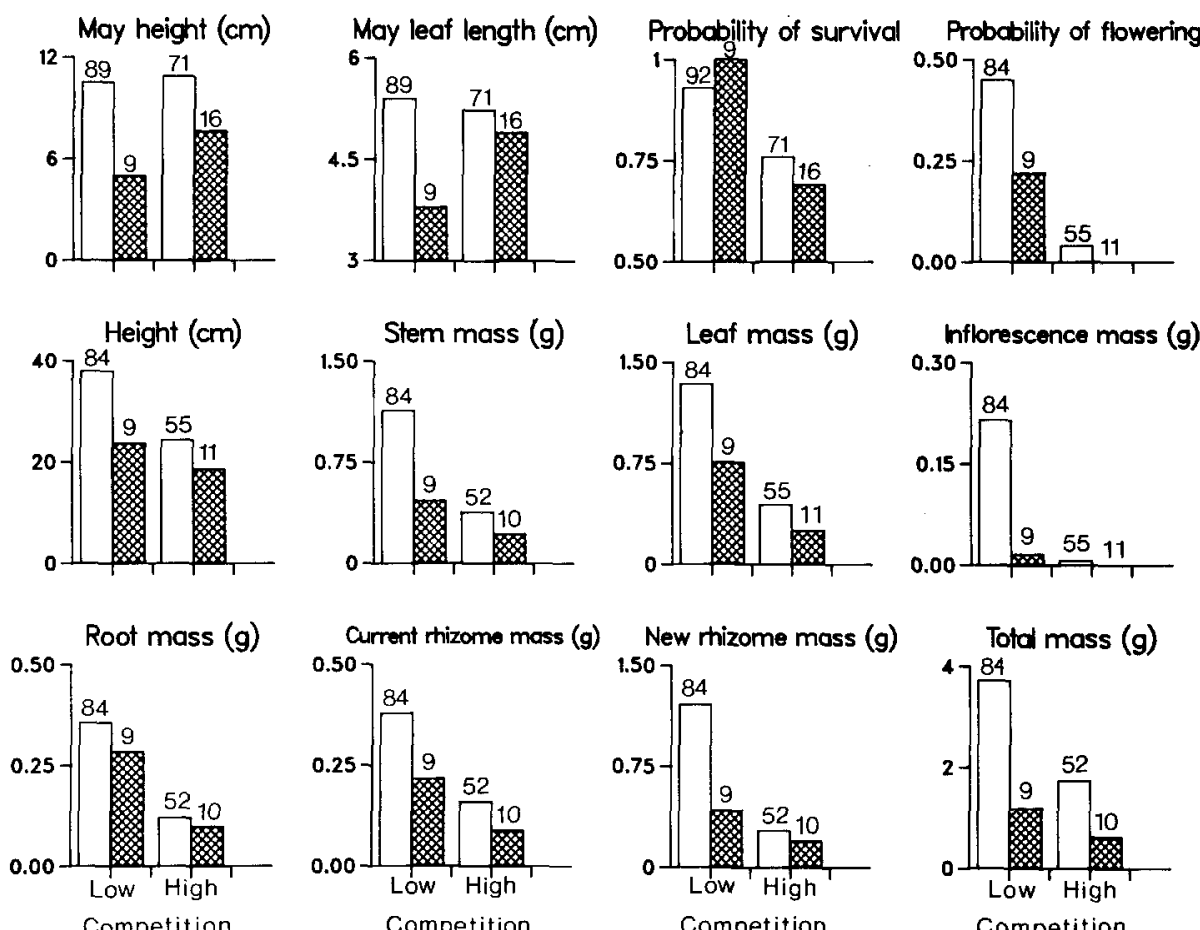

Competition

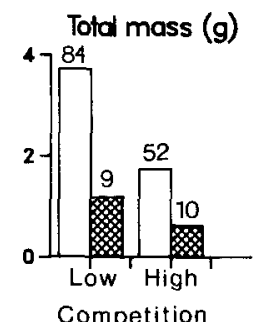

Fig. 1. Effects of competition and herbivore damage in May on transplant performance. Open histograms represent transplants with none-light herbivore damage and shaded histograms represent transplants with heavy herbivore damage. Statistical analyses of these data are reported in Table 3. Sample sizes are above each histogram
Table 3. Effect of competition treatment and herbivore damage on transplant characters (two-way ANOVA's or G-tests). All October size characters were log-transformed prior to analysis

$\begin{array}{llll}N & \begin{array}{l}\text { F com- } \\ \text { petition }^{\text {a }}\end{array} & \begin{array}{l}\text { F her- } \\ \text { bivore }^{\mathrm{a}}\end{array} & \begin{array}{l}\text { Finter- } \\ \text { action }^{\mathrm{a}}\end{array}\end{array}$

\section{May transplant size}

\begin{tabular}{|c|c|c|c|c|}
\hline Height & 185 & $5.60 *$ & $28.22 * * *$ & $5.74 *$ \\
\hline Length longest leaf & 185 & $4.69^{*}$ & $9.66 * * *$ & $6.81^{*}$ \\
\hline \multicolumn{5}{|l|}{ October transplant size } \\
\hline Height & 159 & $14.60^{* * *}$ & $17.21 * * *$ & 1.25 \\
\hline Stem mass & 159 & $32.34 * * *$ & $19.68 * * *$ & 1.06 \\
\hline Leaf mass & 159 & $22.95 * * *$ & $6.28^{*}$ & 0.68 \\
\hline Root mass & 155 & $24.48^{* * *}$ & 0.97 & 0.00 \\
\hline Current rhizome mass & 155 & $30.15 * * *$ & $12.62 * * *$ & 0.01 \\
\hline New rbizome mass & 155 & $6.04 *$ & $2.92^{+}$ & 1.62 \\
\hline Inflorescence mass & 159 & $3.12^{+}$ & 2.57 & 2.20 \\
\hline \multirow[t]{2}{*}{ Total mass } & 155 & $36.07 * * *$ & $14.98 * * *$ & 0.11 \\
\hline & $N$ & $\begin{array}{l}\text { G com- } \\
\text { petition }^{b}\end{array}$ & $\begin{array}{l}\text { G her- } \\
\text { bivore }^{b}\end{array}$ & $\begin{array}{l}\mathrm{G} \text { inte } \\
\text { action }\end{array}$ \\
\hline
\end{tabular}

\section{Transplant demography}

\begin{tabular}{lllll} 
\% survival & 189 & $14.08^{* * *}$ & 0.57 & 0.97 \\
\% flowering & 161 & $39.03^{* * *}$ & $3.86^{*}$ & 0.00 \\
\hline
\end{tabular}

${ }^{+} P \leq 0.10,{ }^{*} P \leq 0.05,{ }^{*} P \leq 0.01, * * * P \leq 0.001$

a Numerator $\mathrm{df}=1$, denominator $\mathrm{df}=N-4$

${ }^{\mathrm{b}} \mathrm{df}=1$

\section{Clonal differences}

Parent clones differed significantly in both height and rhizome mass (Table 4). Clonal differences in transplant characters depended on the particular character (Table 4).
Clones did not differ in probability of emergence or of heavy herbivore damage in May, although size at the May census, especially height, did differ among clones (Table 4). Survival to October was only marginally different among clones but probability of flowering of surviving transplants was highly significantly different. Total transplant biomass in October did not differ among clones, but height and several of the biomass components did differ among clones (Table 4).

The average differences among clones shown in Table 4 could either be accentuated or masked by the strong effects of initial size and of competition treatment and herbivore damage already discussed. Unfortunately the full model (clone $\times$ competition $\times$ herbivore damage with initial size as a covariate) could not be analysed because too few transplants had heavy herbivore damage in each clone (only a total of 25 of the emerged transplants). Therefore results are reported from two-way ANOVA's for effects of competition and clone using all transplants and using only the transplants with none-light herbivore damage to reduce the variation among transplants within clones due to environmental factors other than competition (Table 5). In addition, to see how parental size and size early in the growing season influence the pattern of differences among clones, two-way ANCOVA's were used to compare October transplant size after adjusting for the effects of parent rhizome mass or May height (Table 5). In none of these ANCOVA's were slopes of October transplant size on the covariate significantly different among clones.

When all transplants were included in the ANOVA of clone $\times$ competition, the results were almost identical to those averaging over all competition treatments and herbivore damage classes in Table 4: only May size, October height and stem mass, and October new rhizome mass differed among clones (Table 5). Results were also identical if transplant size was adjusted for parent rhizome mass 
Table 4. Results of comparisons among clones, averaged over all competition treatments and herbivore damage classes. $F$ values from one-way ANOVA's are reported for size characters and $G$ values from one-way G-tests are reported for demographic parameters. October size characters were log-transformed prior to analysis

\begin{tabular}{lcc}
\hline Character & $N$ & F clone \\
\hline Parent ramet size & & \\
Height & 178 & $49.04^{* * *}$ \\
Rhizome mass & 197 & $7.07^{* * *}$ \\
May transplant size & & \\
Height & 185 & $3.93^{* * *}$ \\
Length longest leaf & 185 & $1.88^{+}$ \\
October transplant size & & \\
Height. & 159 & $2.68^{* *}$ \\
Stem mass & 159 & $2.06^{*}$ \\
Leaf mass & 159 & 1.10 \\
Root mass & 155 & 1.41 \\
Current rhizome mass & 155 & 0.64 \\
New rhizome mass & 155 & $3.36^{* * *}$ \\
Inflorescence mass & 159 & $2.05^{*}$ \\
Total mass & 155 & 0.92 \\
& & \\
\hline
\end{tabular}

Transplant demography

G. clone

\begin{tabular}{lll}
\hline$\%$ Emergence & 198 & 14.43 \\
$\%$ Heavy herbivore damage & 185 & 11.14 \\
$\%$ Survival & 189 & $15.02^{+}$ \\
$\%$ Flowering & 159 & $29.02^{* * *}$ \\
\hline
\end{tabular}

${ }^{+} P \leq 0.10, * P \leq 0.05, * * P \leq 0.01, * * * P \leq 0.001$

${ }^{\text {a }}$ Numerator $\mathrm{df}=9$ ( 8 for parent height $)$, denominator $\mathrm{df}=N-10$ ( 9 for parent height)

b $\mathrm{df}=9$
(Table 5). Adjusting for May height, however, eliminated the significant differences in October height and stem mass, leaving only new rhizome mass different among clones (Table 5).

In contrast, when the analysis was restricted to transplants with none-light herbivore damage, all measures of transplant size except inflorescence mass differed among clones at a weak significance level $(P \leq 0.10)$ and almost all differed at stronger significance levels, either without considering earlier size or adjusting for parent rhizome mass (Table 5). However, again, differences among clones were much weaker when October size was adjusted for size in May, although most characters still differed among clones at a weak significance level $(P<0.10)$ (Table 5).

To show the response of each clone to the competition treatments, I used the values adjusted for parent rhizome mass and excluded transplants with heavy herbivore damage (Fig. 2). For each character, unadjusted clonal means, means adjusted for parent rhizome mass and means adjusted for May height were all highly positively correlated with each other within each competition treatment. Thus, incorporating the effects of earlier size does not change the rankings among clones in October size, although it does change the significance level of differences among clones.

For almost all the October size measures, differences among clones were much clearer under low competition than under high competition (Fig. 2). This result is not a function of greater variability among transplants within clones under intense competition and so less statistical power to detect differences. In fact, the coefficients of variation within clones for all of the October size measures tended to be larger under low competition than under high competition on average, although the difference was significant only for stem mass ( $60 \%$ vs. $42 \%$, low vs high competition, paired $\mathrm{t}=2.61, N=10, P<0.05)$ and total mass $(65 \%$ vs. $44 \%$, low vs. high competition, paired $\mathrm{t}=2.28, N=10$, $P<0.05)$.

Table 5. Effects of clone on transplant size characters from twoway (clone $\times$ competition) ANOVA's (unadjusted) or ANCOVA's (using parent rhizome mass or May height as covariates). Degrees of freedom for all $F$ values are $9, N-20$. F values for the effects of competition were not significant for the May size variables and highly significant $(P<0.001)$ for all October size variables in all the analyses. See text for interaction effects. October size characters were log-transformed prior to analysis

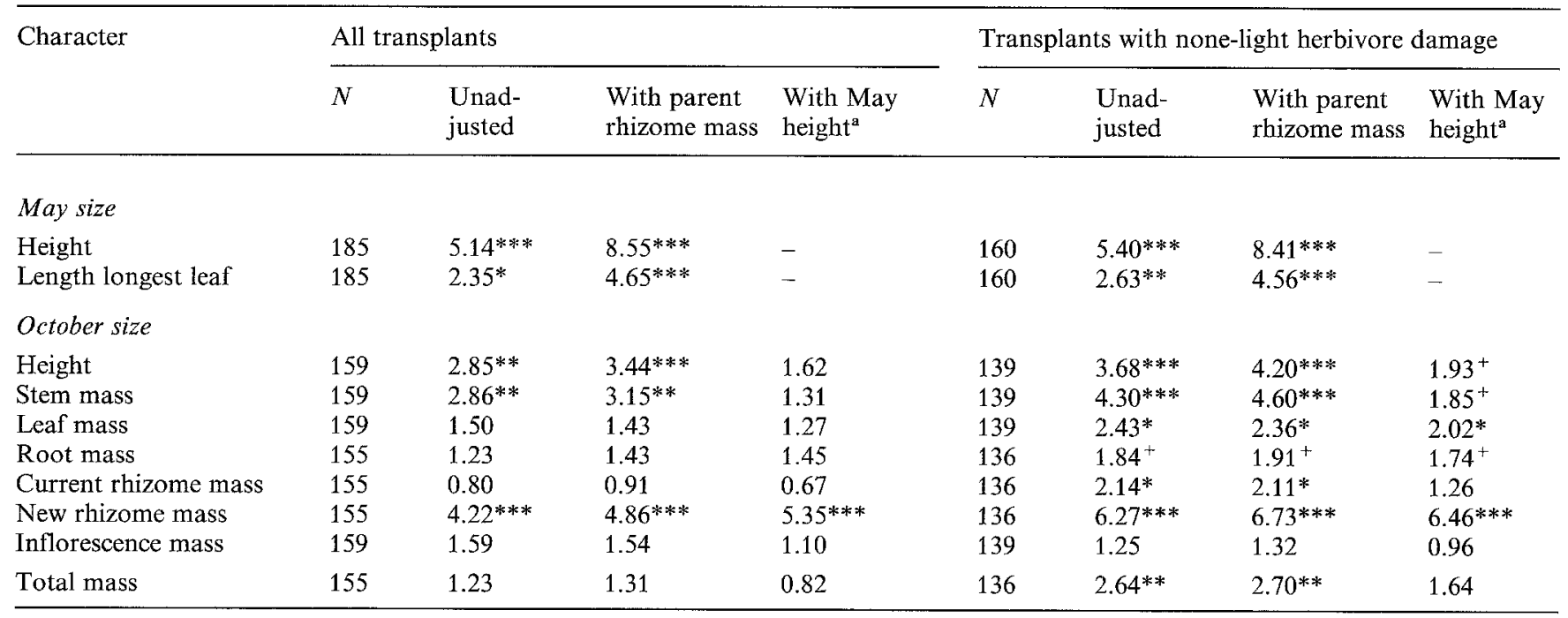

$+P \leq 0.10, * P \leq 0.05, * * P \leq 0.01, * * * P \leq 0.001$

a $N=N-4$ because 4 transplants did not emerge until after the May census 

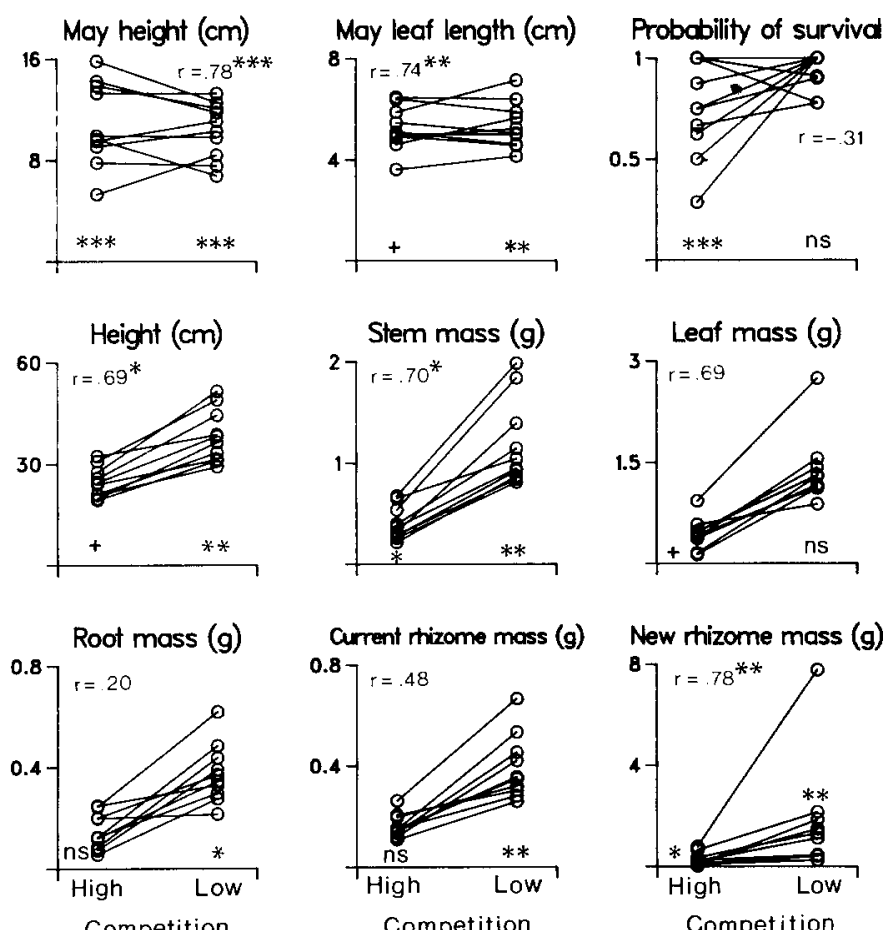

Competition

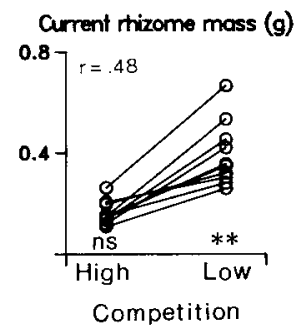

Competition
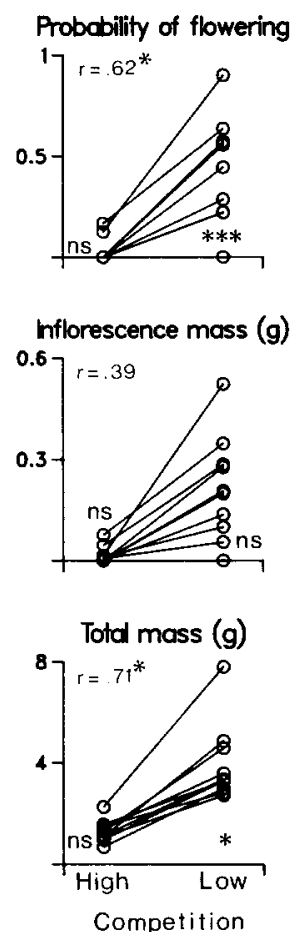

Fig. 2. Performance of each clone under low and high competition. Means for each clone for all the May and October size measures are adjusted for the effects of parent ramet rhizome mass. Only transplants with none-light herbivore damage are included. The $r$ values are from correlations of clonal means in low vs. high competition. Also shown are significance levels of differences among clones under low and under high competition from oneway ANCOVAs (parent ramet rhizome mass as covariate). Statistical analyses of these data are reported in Table $5 .{ }^{+} p \leq 0.10$, ${ }^{*} p \leq 0.05,{ }^{* *} p \leq 0.01,{ }^{* * *} p \leq 0.001$

\section{Clone $\times$ competition interactions}

For most measures of clonal performance, all clones responded to competition in a similar way. The interactions between competition and clone were significant only for new rhizome mass $(P<0.05$ for 5 of the 6 analyses in Table 5) and survival $(\mathrm{G}=21.45, \mathrm{df}=9, P<0.05$ for all transplants; $\mathrm{G}=22.44$, $\mathrm{df}=9, P<0.01$ for transplants with nonelight herbivore damage). The similarity of response to competition among clones is also indicated by the positive correlations of clonal means between low and high competition for all May and October size measures (Fig. 2). The correlations are, however, weak (and nonsignificant) for root mass, current rhizome mass, and inflorescence mass which have the smallest $F$ values for differences among clones (Table 5). For survival, the values for each clone were (nonsignificantly) negatively correlated between treatments, consistent with the indication from the G-test that the relative performance of clones differed between competition treatments.

\section{Discussion}

\section{Effects of environment}

The over $50 \%$ reduction in the biomass of potentially competing plants in the low competition (herbicided) plots was associated with significantly greater transplant survival, flowering, and size in October. Other field experiments in herbaceous communities have almost invariably also found strong positive effects of vegetation removal on survival and growth of remaining plants (see Harper 1977; Connell 1983; Schoener 1983 for reviews and Goldberg 1987; Werner 1988 for field competition experiments with Solidago). Heavy herbivore damage recorded in May also was associated with decreased transplant size in May and most measures of October transplant performance, although the effects were generally not as strong as those of competition.

Significant interactions between the effects of competition and heavy herbivore damage only occurred for transplant size in May, when the combined effects actually resulted in larger transplants. Because the competition treatments were initiated only 10 days before measurements of May size and herbivore damage, it is likely that this result is a consequence of higher probability of attack by herbivores of larger transplants rather than an interactive effect on growth rate of transplants. Because transplants that were larger in May also tended to be larger in October, the fact that larger plants seemed to be damaged in May under high competition may have reduced the possibility of detecting multiplicative negative effects on October size, i.e. unexpectedly small transplants with both heavy herbivore damage in May and large biomass of neighboring plants throughout the season.

\section{Effects of parent clone}

Although there are now numerous published studies of genetic differences among populations in plants, relatively few studies have examined expression of genetic differences among individuals from the same population under field conditions. For perennials, most such studies have used clonal transplants and, in general, have found at least some differences (Turkington and Harper 1979; Schmid 1985; Kelley and Clay 1987). There are two important caveats about the use of clonal material to investigate the genetic basis of individual differences. First, because location of the parent clone may influence performance of the transplants, genotypic effects cannot be distinguished from such carryover effects (Hume and Cavers 1981). Although effects of parental environment could be transmitted in several ways, one important way is through initial size of the transplants. Because the significant differences among clones remained after adjusting for parental size, it seems likely that the clonal differences in transplant performance are at least 
partially genetically based. Second, single, isolated ramets may behave very differently from ramets connected to large clones. Ramets within $S$. canadensis clones show considerable interdependence (Hartnett and Bazzaz 1983, 1985b) that could result in connected ramets experiencing a less heterogeneous environment than isolated ramets and so less phenotypic differentiation among clones in the field.

The extent to which differences were detected among clones in this study depended heavily on the level of environmental heterogeneity in the analysis. Many fewer transplant characters differed when clones were compared averaging over all competitive environments and herbivore damage classes then when variance within clones was reduced by including only the transplants with none-light herbivore damage and incorporating competitive environment in the analysis. Thus, variance in a factor that is independent of clone (clones did not differ in probability of heavy herbivore damage), can mask phenotypic expression of differences among clones, and thus the potential for selection among clones.

The extent to which differences among clones were expressed also depended on the type of environment: many more characters were different under low competition than under high competition. Similar results have been found in several studies comparing populations under favorable an unfavorable conditions as defined by mean plant performance (Heywood and Levin 1984; Hartnett et al. 1987; Schwaegerle and Bazzaz 1987). If these results are general for within population comparisons it suggests greater potential for selection to act on differential fitness among genotypes (not just phenotypes) under more favorable abiotic or biotic conditions. For $S$. canadensis, the less favorable environment (high competition treatment) is the more rea listic situation for the life history stage used in the experiments. Adults from large rhizomes as used in this experiment are only likely to be found in later successional fields, with high vegetation biomass and mostly perennial competitors-conditions under which little clonal differentiation was expressed in this experiment. It therefore seems likely that relatively little potential exists for selection to act differentially among the clones in the field, although, of course, selection on seedling stages could still be strong.

Finally, the extent of phenotypic differentiation detected among clones also differed among the transplant characters. Individual biomass components often differed among clones, even when total transplant mass did not. The strongest differences (highest significance level in all analyses and apparent even when averaged over environments) were in height characters (including stem mass), vegetative reproduction (allocation to new rhizomes), and sexual reproduction (probability of flowering). This is not a consequence of greater statistical power to detect differences because of less variability within clones in these characters. While October height was the least variable size measure within clones $(25 \%$ and $33 \%$ mean c.v. in high and low competition, respectively), new rhizome mass was the most variable within clones of all the vegetative characters measured (96\% and $98 \%$ mean c.v. in high and low competition, respectively).

The weakening of differences among clones in October size characters when they were adjusted for transplant height in May indicates that most of the differences in final size among clones are due to clonal size differences expressed early in the growing season that carry through the growing season and not in growth rate over the season. The one exception is new rhizome mass, which remained highly significantly different among clones even after adjusting for May height. It should be noted, however, that the differences in new rhizome mass could reflect differences in timing of production and elongation of new rhizomes rather than in total biomass eventually allocated to new rhizomes.

\section{Clone $\times$ environment interactions}

Despite the differences observed among clones, especially under low competition, and the strong effects of competition treatment on almost all transplant characters, the $S$. canadensis clones do not seem to differ in response to competitive environment (few significant clone $\times$ competition interactions). This lack of difference among clones in response to total biomass of neighbors contrasts with several other studies using clonal perennials that have found significant differences among clones in response to more subtle aspects of the competitive environment. Trifolium repens genets from the same population have been found to differ in response to the species of neighboring plants (Turkington 1979; Turkington and Harper 1979) and even the genotype of neighboring plants (Aarssen and Turkington 1985a). Similarly, Kelley and Clay (1987) found that interspecific competitive ability was genotype-specific for one species of perennial bunchgrass, Danthonia spicata, although not for Anthoxanthum odoratum. If relative success of clones of $S$. canadensis similarly depends on species and/or genotype of neighbors, using total biomass as the sole descriptor of competitive environment could have masked subtle differences in competitive ability among clones.

An alternative explanation for the lack of differences in competitive ability among these clones is that the parent clones represent the survivors after selection for good competitors out of the many more genotypes that started from seed in the field. The parent ramets were collected from clones growing in a 32-year old field and these clones probably established from seed much earlier in succession (Hartnett and Bazzaz 1985a; Goldberg and Werner 1983). Consistent with this explanation, Schmid (1985) found significant differences in growth among clones of Prunella vulgaris and Bellis perennis only in the youngest of 3 populations studied.

Consistent with the lack of clone $\times$ competition interactions, no tradeoffs are apparent between performance in low competition and performance in high competition. Rankings of mean size of each clone are generally similar between the high and low competition treatments, suggesting that whatever traits are responsible for relatively good performance of a clone are the same in both environments. An important consequence of these results is that it is unlikely that selection favors different clones within early vs. later successional stages or among sites at a given successional stage that vary in vegetation structure.

Acknowledgements. This research was supported by the National Science Foundation DEB81-11315 to DEG and P.A. Werner and a Rackham Faculty Research Grant from the University of Michigan. I thank Tom Miller and Lisa Bradshaw for field and laboratory assistance and L. Aarssen, L. Gibbs, T. Miller and A. Winn for valuable comments on the manuscript. Kellogg Biological Station Contribution No. 629. 


\section{References}

Aarssen LW, Turkington R (1985a) Biotic specialization between neighbouring genotypes in Lolium perenne and Trifolium repens from a permanent pasture. J Ecol 73:605-614

Aarssen LW, Turkington R (1985b) Competitive relations among species from pastures of different ages. Can J Bot 63:2319-2325

Antonovics J (1984) Genetic variation within populations. In: Dirzo R, Sarukhan J (eds) Perspectives on plant population ecology. Sinauer Associates, pp 229-241

Baird DD, Upchurch RP, Homesley WB, Franz JE (1971) Introduction of a new broadspectrum postemergence herbicide class with utility or herbaceous perennial weed control. Proc Northeast Weed Contr Conf 26:64 68

Connell JH (1983) On the prevalence and relative importance of interspecific competition: evidence from field experiments. Am Nat 122:661-696

Dixon WJ (1983) BMDP statistical software. University of California Press, Berkeley

Ellstrand NC, Roose ML (1987) Patterns of genotypic diversity in clonal plant species. Am J Bot 74:123-131

Ennos RA (1985) The significance of genetic variation for root growth within a natural population of white clover (Trifolium repens). J Ecol 73:615-624

Ford H (1981) Competitive relationships amongst apomictic dandelions. Biol J Linn Soc 15:355-368

Fowler NL, Antonovics J (1981) Small scale variability in the demography of transplants of two herbaceous species. Ecology 62:1450-1457

Garbutt K, Bazzaz FA (1987) Population niche structure: differential response of Abutilon theophrasti progeny to resource gradients. Oecologia (Berlin) 72:291-296

Goldberg DE (1987) Neighborhood competition in an old-field plant community. Ecology 68:1211-1223

Goldberg DE, Werner PA (1983) The effects of size of opening in vegetation and litter cover on seedling establishment of goldenrods (Solidago spp.). Oecologia (Berlin) 60:149-155

Hamrick JL (1979) Genetic variation and longevity. In: Solbrig OT, Jain S, Johnson GB, Raven PH (eds) Topics in plant population biology. Columbia University Press, New York, pp 84113

Harper JL (1977) Population biology of plants. Academic Press, New York, pp 892

Hartnett DC, Bazzaz FA (1983) Physiological integration among intraclonal ramets in Solidago canadensis. Ecology 64:779-788

Hartnett DC, Bazzaz FA (1985a) The genet and ramet population dynamics of Solidago canadensis in an abandoned field. J Ecol $73: 407-413$

Hartnett DC, Bazzaz FA (1985b) The integration of neighborhood effects by clonal genets in Solidago canadensis. J Ecol $73: 415-427$
Hartnett DC, Hartnett BB, Bazzaz FA (1987) Persistence of $\mathrm{Am}$ brosia trifida populations in old fields and responses to successional change. Am J Bot 74:1239-1248

Heywood JS, Levin DA (1984) Genotype-environment interactions in determining fitness in dense, artificial populations of Phlox drummondii. Oecologia (Berlin) 61:363-371

Hume L, Cavers PB (1981) A methodological problem in genecology. Seeds versus clones as source material for uniform gardens. Can J Bot 59:763-768

Kelley SE, Clay K (1987) Interspecific competitive interactions and the maintenance of genotypic variation within two perennial grasses. Evolution 41:92-103

Martin MM, Harding J (1981) Evidence for the evolution of competition between two species of annual plants. Evolution 35:975-987

Schmid B (1985) Clonal growth in grassland perennials. III. Genetic variation and plasticity between and within populations of Bellis perennis and Prunella vulgaris. J Ecol 73:819-830

Schoen DJ, Stewart SC, Lechowicz MJ, Bell G (1986) Partitioning the transplant site effect in reciprocal transplant experiments with Impatiens capensis and I. pallida. Oecologia (Berlin) $70: 149-154$

Schoener TW (1983) Field experiments on interspecific competition. Am Nat 122:240-285

Schwaegerle KE, Bazzaz FA (1987) Differentiation among nine populations of Phlox: response to environmental gradients. Ecology 68:54 64

Solbrig OT, Simpson BB (1977) A garden experiment on competition between biotypes of the common dandelion (Taraxacum officinale). J Ecol 65:427-430

Turkington R (1979) Neighbour relationships in grass-legume communities. IV. Fine scale biotic differentiation. Can J Bot $57: 2711-2716$

Turkington R, Harper JL (1979) The growth, distribution and neighbor relationships of Trifolium repens in a permanent pasture. IV. Fine-scale biotic differentiation. J Ecol 67:245-254

Werner PA (1988) Goldenrods (Solidago spp.) on edaphic gradients: a field experiment of competition vs. tolerance using reciprocal transplants. Ecol Monogr (in press)

Werner PA, Bradbury IK, Gross RS (1980) The biology of Canadian weeds. 45. Solidago canadensis L. Can J Plant Sci $60: 1393-1409$

Zangerl AR, Bazzaz FA (1983) Plasticity and genotypic variation in photosynthetic behavior of an early and a late successional species of Polygonum. Oecologia (Berlin) 57:270-273

Zangerl AR, Bazzaz FA (1984) Niche partitioning between two phosphoglucoisomerase genotypes in Amaranthus retroflexus. Ecology 65:218-222

Received November 30, 1987 